\title{
Remarks on Dr. Petersen's Report of the Danish Biological Station for 1895.
}

\author{
By
}

Ernest W. L. Holt.

Iт may be predicted of a Report by Dr. Petersen that it is sure to contain matter of great interest, both to the ichthyologist and to the student of fishery questions; and the volume for 1895 is assuredly no exception to the rule.

The subject dealt with is the plaice fishery of the Lim fjord, an arm of the sea which pierces the Danish peninsula from Thyboron, on the west coast, to Hals, on the Cattegat. Such a geographical feature is quite without parallel in our comparatively mountainous countries, and may even be said to present difficulties of comprehension to those who have not had an opportunity of visiting Denmark. Indeed, the physical conditions are so different from our own, that it must be at once acknowledged that the mass of information so carefully collated by Petersen cannot be made of direct use in connection with any of our own fisheries. Indirectly, however, the Danish work will be found to be of the highest importance, and well worth the attention of those concerned with British fisheries.

A glance at Petersen's map shows that the Lim fjord consists of "brednungs," or broads, connected with each other by somewhat narrow channels of various lengths. The westernmost (Nissum) broad communicates with the sea (since the beginning of the present century) by means of an inconsiderable opening in the barrier ridge of Hasboöre, while the Liv broad, the easternmost, and by far the largest of the series, is separated from the Cattegat by a long and, for the most part, narrow sound. Previous to the breakdown of the Hasboöre barrier we learn that plaice were only found in the sound last mentioned, viz., that between Hals and Lögstör, and only then, as now, in quite inconsiderable numbers, even in that part. Consequently the fish, which now form the object of a most important 
industry, are comparatively new-comers, and belong, not to one of the stunted Baltic races, but, as Petersen incidentally shows, to the largest of the North Sea races, viz., the one familiar to Grimsby fishermen. It is, moreover, most important to note that the plaice of the Lim fjord does not as yet appear to have become a true native, the stock of fish annually taken being merely those which have entered the fjord in the early stages of their career. Petersen evidently holds the conviction that the fish does not breed there at all; but rightly guards bimself against an absolute statement to that effect until his evidence shall be more complete. It is equally evident that the contrary opinion is not unkwown in the locality; but certainly all that we know in this country about the breeding of the plaice must be taken as evidence of the correctness of Petersen's views on this matter.

To what extent the reproductive activity may be affected by conditions of mere salinity is a question to the solution of which we are not helped by the recorded observations of any writer; and, as it happens, no details of specific gravity, etc., are given in the present Report, though we learn, incidentally, that the salinity, if that be really a desideratum, must be sufficient for the reproduction of the rockling, sprat, and flounder. That these fish will spawn in narrow waters we know from our own experience at home, but except where, as on the west coast of Ireland, the rapid declivity limits the habitable area to a comparatively narrow strip, I cannot call to mind any record of plaice spawning close inshore. In the Lim fjord the fish is limited to an area of 614 square miles, of which only 283 square miles contain three or more fathoms of water; and, as Petersen shows, the Liv and Thisted broads, which comprise about one-half of the whole area, are seldom, if ever, reached at all by plaice under natural conditions.

That a few fish are occasionally found with ripe ovaries is, I think, rightly held by Petersen to be no proof that actual breeding takes place there, since we know, from our experience of aquaria, that fish will yearly develop spawn, but will not shed it until thoroughly acclimatised. Even in the feral condition one occasionally meets with fish in which the ripe ova have remained to decompose within the ovaries, and I can recall at least one instance in which such a condition appeared to be directly due to the creatures having returned too soon, or having never left the estuarine waters.

That the fish are not actually land-locked in the fjord is evident from the fact that they got in there, but very few seem to get out again, for the sufficient reason that the fishermen catch practically all that are marketable; and it is worth while to note that it only takes about twelve days' fishing in each broad to exhaust the annual supply. 
Fishing appears to be carried on entirely by means of seines, of a fixed pattern of mesh, and during a season which opens on the 1st September, while a law has for some time been in force whereby the sale of plaice less than $9 \frac{3}{4}$ inches long is prohibited, though there is no means of preventing the use of undersized fish for agricultural purposes. However, it does not appear from anything in the Report that there is any depreciation in the annual take, though the annual drain on the stocking power of the outside fish is so considerable, and to all intents and purposes wholly uncompensated by the return of mature fish to the open sea.*

Human intervention is therefore here required, not to arrest a decrease of the general supply, but to effect an increase in the number of large fish, for of the small there seem to be enough and to spare. The problem is really, as appears from the Report, how to get enough fish into the inner broads, i.e., Liv broad and its subsidiary lagoons, which, forming about one-half of the total area of the fjord, are practically never reached by plaice under natural conditions. Petersen's observations lead him to the knowledge that the young fish move very slowly up the fjord, and reach the inner expanses, if at all, only in very inconsiderable numbers.

The reason is not far to seek, for, in the first place, nearly all the fairsized individuals find their way into the hands of the fishermen; while if any escape they must, to reach the inner waters, traverse dense grassfields (zostera), whither the plaice "come but rarely, and where it has no reason at all to go, as it does not know there is plenty of food for it further up." A somewhat extensive experience of fishery literature supplies me with no more striking instance of common-sense expressed in simple language.

But if the fish does not know where he would be well off, the fjord fish merchants seem to have perceived that it is to their interest to help him on, for we learn that since 1892 there has been carried on a system of State-aided transplantation, whereby in 1895 alone more than 80,000 fish were transferred from the North Sea to the inner broads. A proportion of these fish were marked by means of holes in the fins, and it is by ascertaining the proportion of marked fish captured later on that Petersen is able to prove, not less to the satisfaction of his readers than of himself, that the inner waters are populated almost, if not entirely, by transplanted fish; while even the unmarked fish support the same conclusion by bearing traces of confinement in a boat's well.

* There is an exactly parallel condition in the Mediterranean, where Professor Marion has shown that the bands of young sardines, which every year enter some of the shallow lagoons near the mouths of the Rhone, neither return to the sea nor survive to reproduce their species within the inland waters. 
It was found by the fishermen, and is proved by Petersen's observations, that plaice grow much more quickly in these inner waters than in the western expansions of the fjord, and, moreover, reach a larger ultimate size, which increases their value, apart from mere question of weight, since very large fish command, from their rarity and excellent condition, an unusual price. It appears, in fact, from the examination of the few sexually mature females available, that the transported fish are similar, in their relations of size and maturity, to the larger of the North Sea races, from which, of course, they are annually bred.*

On the other hand, the plaice in the outer broads show a tendency to become mature at a somewhat smaller size. There is, perhaps, to the biologist nothing in the whole Report of greater interest than this last observation, since we seem to have before us the possibility of the establishment of two apparent size-races, derived from common parentage, operating under comparatively slight differences of environment. There is, of course, nothing to show that the differences would be transmitted, even if (1) the fishermen spared any fish to reproduce their race within the fjord, and (2) if reproduction, as seems to be doubted, is possible there at all.

In any case, the study of biological problems is pretty generally known to bring no grist to the mill, and as Petersen's duties are to the fishermen and not to the ichthyologist, he clearly regards the annual fishing-out of the possible breeders with absolute complacency. In his opinion, undoubtedly a sound one, the preservation of breeders might yield unexpected results; and I would venture to go further and predict that, if any result in the way of reproduction were achieved, it would inevitably be in the ultimate peopling of the fjord with one or more stunted races of little commercial value.

Granted that the fish grow more quickly and larger in the inner broads, the question arises, Why is this the case? The fisherman's answer, that the bottom is more suitable than in the outer part, does not appear to be based on a profound study of the benthos, since Petersen is unable to detect any particular difference in this respect. On the other hand, he produces figures to show that there is a very marked difference in the number of fish which are found per acre in the different parts; and as the number is infinitely the greater in the outer broads, he concludes that in the latter the fish are stunted in their growth by "over-population." I have quoted the word used, which is not qualified by any explanation, but is surely intended to be understood as over-competition for a limited available food-supply. Otherwise,

* Since Dr. Petersen is good enough to refer to me in this connection, I must remind him that I proposed 17 inches as the biological limit between mature and immature fish, and not as a size-limit for legislative purposes. 
since oxygen may be presumed to be in ample abundance, I do not see that mere crowding need unfavourably react on the growth of the fish. In any case, one may venture to suggest that an attempt to tabulate the stomach contents of fish, and the proportionate quantity of food organisms per acre, would greatly enhance the interest of the statistics given.

Granted that overcrowding means in great part underfeeding, there seems no reason to quarrel with the conclusions which Petersen bases on his statistics; and if I am constrained to criticise the figures themselves, it is chiefly in regard to the manner in which they are set forth.

The statistical work was undertaken, as we have seen, with a view to ascertaining the local population in the different broads, and the fishing was done entirely with seines.

The word seine is capable of rather a wide interpretation in this country, and probably in Denmark also; but as no details are given, one must assume that the nets used, if not of uniform pattern, were at least of approximate efficiency in proportion to their sizes. It appears that the plaice-seines are hauled into boats in about three fathoms of water, and may be supposed to be similar in general make to the "tuck-net" of the Plymouth district, since an ordinary bottomseine without a central bunt could not easily be raised in so much water without risk of losing the fish. In calculating the results, Petersen shows that a seine shot from a boat covers, theoretically, a triangular area of ground, marked out by the net as base and the two lines as sides. Thus, if twenty fathoms of line are used, and the net is twenty fathoms long, it covers, theoretically, an equilateral triangle, the sides of which are each twenty fathoms. On this basis the area covered by a number of hatls is computed in Danish "Tonder Land," and the population per "T. L." ascertained by proportional assignment of the total catch of fish.

While my own experience leads me to the belief that the seine is the most efficient engine that could be used for the statistical enumeration of bottom fish in shallow waters, it is perhaps my ignorance of the local conditions which leads me to suspect that Petersen, although he acknowledges that his figures are only approximate, hardly lays sufficient stress on the possibilities of error.

In this country the state of the tide has the greatest possible effect on the efficacy of a seine, not only in determining, by its rise and fall, (1) the amount of ground that can be covered, and (2) the movements of the fish, but also in influencing the action of the net. So far as the first question is concerned, we learn that the rise and fall in the fjord is only about a foot in extent, so that it need not be considered; 
but nothing is said as to the force of the tide, except that the tides are strong at the Thyboron end. I do not know how far we may be justified in inferring, from the insignificance of the rise and fall, that there are no violent tide currents in the inner broads and channels; but if such really exist, the efficacy of the net must be largely dependent, as here, on the tide period.

It is also recognized that the weather exercises an important influence on seining. Even in waters far narrower than those of the Lim fjord broads, the wind, when not strong enough to stop it altogether, may seriously interfere with its success; while, though fishing operations may not be hampered, it is very generally believed, if not actually known, that conditions of wind and temperature react most powerfully on the distribution of the fish. No detailed information being forthcoming,* we are left to assume that the hauls on which the comparative statistics are based were all made under practically identical conditions of tide, weather, temperature, etc., which is a very large assumption.

I have perhaps laid too much stress on this matter, for there is no reason to doubt the general accuracy of Petersen's conclusions as to the relative numbers of fish in the different areas; and if he thinks that, by converting his actual figures into more or less approximate enumerations of population per acre, the result is more easy of general comprehension, he is more than probably right.

We have now to deal with the recommendations which are suggested by the conditions already ascertained; and it is obvious that only two courses are open, i.e., either (1) to preserve the fish with a view to their reproduction, and to the consequent population of the now comparatively uninhabited inner broads, or (2) to annually stock these broads with the largest number of young fish that can thrive (i.e., grow rapidly) therein.

We have already seen that Petersen is no friend to preservation. $\mathrm{He}$ is not sure that it would result in reproduction, while he sees that if reproduction occurred it would have the effect of encumbering the broads with a number of small, hungry fish that would be of no value for some years, besides entailing some hardship by the imposition of a very high size-limit. I cannot controvert his arguments, the more so since, as I have already said, I believe that reproduction would ultimately result in a stunted race.

The Lim fjord men have, as one may say, at their very doors a vast natural and practically inexhaustible hatchery-or rather nursery-to which they may resort in all weathers with the certainty of finding as

* In Appendix III., the diary of professional fishing operations, the weather is noticed, but only when bad enough to entirely suspend fishing operations. 
many fish as they have time to transport. Small wonder, therefore, that Petersen inclines to the restocking method, and is only troubled as to the maximum number of fish which may be safely dumped down on the inner broads.

We learn from his previous writings that he is no admirer of the suggestions put forward by myself, in common with some other British naturalists, as to the necessity of preserving small fish; and truly, if we had the same opportunities of replenishing our depleted grounds as present themselves in the fjord, it is little we should reck of the doings of our inshore fishermen or of our trawlers on the eastern grounds. The cases, however, are exactly opposite. Petersen has to deal with too many young fish and not enough accessible ground for them to thrive on; while we are confronted with an unlimited extent of suitable ground and an enormous destruction of the very fish which, if unmolested, would come to populate these grounds. I do not see that there is any necessary want of harmony in these apparently opposite views. Apart from our own coasts, the destruction of which I have seen cause to complain affects the outer fringe of the continental small fish, which would ultimately set offshore; and I think that if the fish were spared to populate the offshore waters in their large condition, our trawlers might be relied on to prevent their having the chance of sending back too many little ones to choke Dr. Petersen's fjords.

With the exception of appendixes giving the figures on which the conclusions are based, the Report ends with the formulation of propositions having in view the regulation and improvement of the fjord plaice fishery. The general object of these propositions we have already seen, viz., the extended transplantation of fish into the inner waters; but there is a rider to the effect that none but the local fishermen should be allowed to participate in the benefits which are expected to accrue. It must be presumed that this is in accordance with the Danish conception of the principles of political economy. In any case, it is the Danish taxpayer's affair, and none of ours.

Incidentally it is proposed that more material and money should be placed at the disposal of the Biological Station, and with all sincerity we may hope that Dr. Petersen will get it, for it is certain to be well used. 